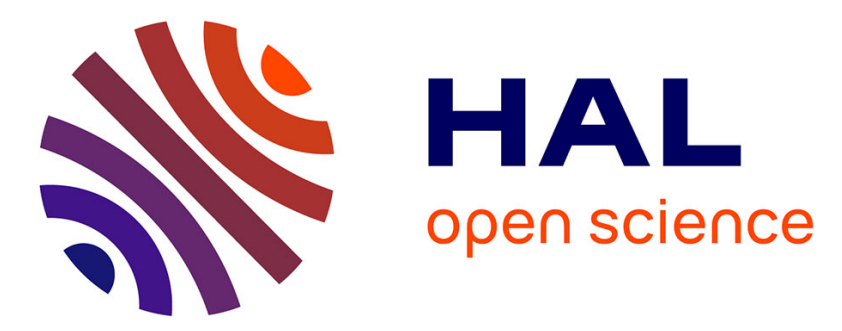

\title{
Modelling land use strategies to optimise crop production and protection of ecologically important weed species
}

David Makowski, Thierry Doré, Jacques Gasquez, Nicolas Munier-Jolain

\section{- To cite this version:}

David Makowski, Thierry Doré, Jacques Gasquez, Nicolas Munier-Jolain. Modelling land use strategies to optimise crop production and protection of ecologically important weed species. Weed Research, 2007, 47, pp.202-211. 10.1111/j.1365-3180.2007.00562.x . hal-01173127

\section{HAL Id: hal-01173127 \\ https://hal.science/hal-01173127}

Submitted on 13 Aug 2019

HAL is a multi-disciplinary open access archive for the deposit and dissemination of scientific research documents, whether they are published or not. The documents may come from teaching and research institutions in France or abroad, or from public or private research centers.
L'archive ouverte pluridisciplinaire HAL, est destinée au dépôt et à la diffusion de documents scientifiques de niveau recherche, publiés ou non, émanant des établissements d'enseignement et de recherche français ou étrangers, des laboratoires publics ou privés. 


\section{WEED RESEARCH}

Modelling land use strategies to optimise crop production and protection of ecologically important weed-species

\begin{tabular}{|c|c|}
\hline Journal: & Weed Research \\
\hline Manuscript ID: & WRE-2006-0040.R3 \\
\hline Manuscript Type: & Original Article \\
\hline $\begin{array}{r}\text { Date Submitted by the } \\
\text { Author: }\end{array}$ & 23-Feb-2007 \\
\hline Complete List of Authors: & $\begin{array}{l}\text { Makowski, David; INRA } \\
\text { Dore, Thierry; AgroParisTech } \\
\text { GASQUEZ, Jacques; INRA } \\
\text { MUNIER-JOLAIN, Nicolas; INRA, UMR Biologie et Gestion des } \\
\text { adventices }\end{array}$ \\
\hline Keywords: & $\begin{array}{l}\text { integrated weed management, biodiversity, yield, agroecology, } \\
\text { sustainable agriculture, crops }\end{array}$ \\
\hline
\end{tabular}

\section{s) ScholarONE"


Revised version 3

$1 \quad$ Modelling land use strategies to optimise crop production

\section{and protection of ecologically important weed species}

3

4 David Makowski ${ }^{1 *}$, Thierry Doré $^{2}$, Jacques Gasquez $^{3}$, Nicolas Munier-Jolain $^{3}$

$6 \quad{ }^{1}$ INRA, UMR 211 INRA/AgroParisTech 78850 Thiverval-Grignon France

$7 \quad{ }^{2}$ AgroParisTech, UMR 211 INRA/AgroParisTech 78850 Thiverval-Grignon France

$8{ }^{3}$ INRA, UMR Biologie et Gestion des Adventices INRA 21065 Dijon France

9

10 Short title: Maintaining plant species in agricultural areas.

$11 *$ Corresponding author

12 David Makowski

13 UMR 211 INRA/AgroParisTech

14 Bâtiment EGER

15 BP 01

1678850 Thiverval-Grignon

17 France

18 Email: makowski@grignon.inra.fr

19 Phone: 33130815992

$20 \quad$ Fax: 33130815425 
Revised version 3

\section{Abstract}

2 There is a need to develop farming systems that enable both a satisfactory level of crop

3 production and good living conditions for natural species. Wildlife-friendly cropping

4 techniques, such as a reduced amount of applied herbicide or a lower crop density, might be

5 adopted in order to maintain populations of weed species of biological interest. An alternative

6 might be to adopt an intensive cropping system in a part of the field and spare the other part

7 as set-aside or field margins, available for the development of natural plant species. The

8 objective of this paper is to present a method to compare two strategies for maintaining a

9 desirable level of abundance of a given species of interest in agricultural areas, specifically (1)

10 a strategy based on a wildlife-friendly cropping system in a large cultivated area and (2) a

11 strategy based on a more intensive cropping system in a reduced area of cultivation. The

12 principle is to calculate the ratio of crop production obtained with strategy (1) to the

13 production obtained with strategy (2) for a given target density of natural species. We show

14 that the value of this ratio, and thus the relative performance of the two strategies, depends on

15 the density of the weed species that can be maintained in an uncultivated ecological area. The

16 method is applied in two case studies to compare the relative performance of wildlife-friendly

17 cropping system and land sparing for maintaining a desirable level of abundance of two plant

18 species with contrasting ecology and preservation goals.

20 Keywords: Adonis aestivalis, biodiversity, cropping system, land use, Poa annua L. 
Revised version 3

\section{Introduction}

2 The intensive use of inputs in crops has caused a decline in biodiversity in European arable

3 ecosystems (Stoate et al., 2001; van Wenum et al., 2004). Such a decline has been well

4 documented for birds (Chamberlain et al., 2000), invertebrates, and plants (e.g. Andreasen et

5 al., 1996; Sutcliffe \& Kay, 2000 ; Green et al., 2005). Concerns about the impact of intensive

6 agriculture on ecosystems are arising both among the European population and policy-makers

7 (Stoate et al., 2001; van Wenum et al., 2004). Gerowitt et al. (2003) have recently proposed that weeds should be considered as ecological goods. Some weed species, e.g. Poa annua L.,

9 are important components of ecosystems because their biomass constitutes a nutrient resource

10 for birds or other vertebrates (Marshall et al., 2003). Other species, such as Adonis species,

11 have drastically declined in abundance in Western Europe (Aymonin, 1976) and agronomists are now trying to define precise land use strategies to preserve these species, among others, 13 from extinction.

However, weeds growing in arable land compete with crops for nutrients, light and water, and are therefore likely to reduce crop yields and the cropping system profitability. There is a need to develop systems leading to satisfactory levels of crop production and maintaining appropriate conditions to support populations of natural species. Several solutions have been proposed such as a reduction of pesticide input (Stoate et al., 2001), the use of arable field margins (Marshall \& Moonen, 2002), or the use of permanent or rotating set-aside (van Wenum et al., 2004), but little is known about the relative efficiency of these 21 solutions.

Wildlife-friendly cropping techniques, like a reduced amount of applied herbicide (de Snoo, 1997), a lower crop density and/or restricted fertiliser inputs (Kleijn \& van der Voort, 1997) might be adopted in order to maintain populations of weed species of biological interest 


\section{Revised version 3}

1 (target species). But the adoption of such techniques is likely to induce a yield loss due to the

2 development of a large weed community. An alternative might be to adopt a land-sparing

3 strategy of using an intensive cropping system in a part of the field and sparing the other part

4 as set-aside or field margins, available for the development of natural plant species. Using this

5 strategy, a high yield would be obtained in the cultivated part of the field, but the absence of

6 crop on the remaining part results in a loss of production for the farmer. According to Green

7 et al. (2005), the optimal choice between a land-sparing strategy and the use of wildlife-

8 friendly cropping techniques depends on the density-yield relationship between population

9 density of a target species growing in a crop and the crop yield. If a small reduction in the

10 farm inputs is likely to trigger a significant increase in the wildlife while resulting in only a

11 small reduction in crop production, then the best strategy to optimize the balance between

12 economy and ecology would be to use all the area for crop production with wildlife-friendly

13 management. However, if any increase in the wildlife may be obtained only through a strong

14 reduction in farm inputs, then the best strategy would be to partition the land area with areas

15 allocated to intensive crop production and areas allocated to wildlife conservation.

The impacts of wildlife-friendly techniques and land sparing on crop production and on weed populations depend on many factors, such as the characteristics of the weed species

18 growing in the field, the weed densities, and the crop yield values. Choosing the best land use strategy is not straightforward. In this paper, we present a method to compare two strategies for maintaining a desirable level of abundance of a given species of interest in the landscape,

21 specifically (1) a strategy based on a wildlife-friendly cropping system in a large cultivated area and (2) a strategy based on a more intensive cropping system in a reduced cultivated 23 area. The proposed method can be used to determine, for each strategy, the area that must remain uncultivated in order to obtain the targeted density of plants. This method can also be 
Revised version 3

1 environment or for a series of environments corresponding to different levels of abundance of 2 the plant species.

There is a close relationship between the model of Green et al. (2005) and our work.

4 Both aim at comparing crop production and population densities of target species resulting

5 from different land use strategies. But the two approaches differ in the method used to

6 estimate crop production and population densities. Green et al. (2005) assessed the relative

7 performance of the wildlife-friendly and intensive land use strategies using the shape of the

8 population density-yield function and, more specifically, the convexity or concavity of this

9 function. Our method is not based on the shape of the density-yield function; the

10 performances of the two land use strategies are compared from measured or estimated values

11 of plant densities and crop yields.

The value of our approach is illustrated through two case studies, namely (i) Poa

13 аппиа, a common grass weed producing many seeds important in the diet of birds and other 14 animal species, and (ii) Adonis spp. as an example of a rare weed species.

\section{Methods}

\section{Cultivated area for a target number of plants}

18 Consider an agricultural area with a surface equal to $S$ and two cropping systems, an intensive

19 one and a wildlife-friendly one, leading to a density of a plant species of ecological interest

20 (e.g. Poa апnua) equal to $d_{I}$ and $d_{W F}$ respectively (plants per unit area). Assume that the

21 density is equal to $d_{U}$ if the field remains uncultivated such as $d_{I}<d_{W F}<d_{U}$. $d_{U}$ is an

22 indicator of the natural abundance of the species in the environment. 
Revised version 3

1 If the intensive cropping system is adopted by the farmer, the number of plants in the field,

$2 \quad Z$, is related to $d_{I}$ and $d_{U}$ by

$3 \quad Z=d_{I} s_{I}+\left(S-s_{I}\right) d_{U}$

4 where $s_{I}$ is the surface of the cultivated area, $d_{I} s_{I}$ is the number of plants obtained in the

5 cultivated part, and $\left(S-S_{I}\right) d_{U}$ is the number of plants obtained in the uncultivated part (set-

6 aside or field margins).

$7 \quad$ By dividing the two sides of Eqn (1) by $S$, we obtain

$8 \quad D=d_{I} f_{I}+\left(1-f_{I}\right) d_{U}$

9 where $D$ is the number of plants of ecological interest per unit area at the field level and $f_{I}$ is

10 the cultivated area divided by the total field area. As $0 \leq f_{I} \leq 1$, we have $d_{I} \leq D \leq d_{U}$.

11 We express the fraction of the field that is cultivated $\left(f_{I}\right)$ as a function of the number of

12 plants $D$. Eqn (2) shows that $f_{I}$ is related to $D$ by

$f_{I}=1 \quad$ if $D=d_{I}$

$13 \quad f_{I}=\frac{d_{U}-D}{d_{U}-d_{I}} \quad$ if $d_{I}<D<d_{U}$

$f_{I}=0 \quad$ if $D=d_{U}$

14 A similar equation can be obtained if the wildlife-friendly cropping system is adopted by the

15 farmer:

$$
f_{W F}=1 \quad \text { if } D=d_{W F}
$$

$16 \quad f_{W F}=\frac{d_{U}-D}{d_{U}-d_{W F}} \quad$ if $d_{W F}<D<d_{U}$

$f_{W F}=0 \quad$ if $D=d_{U}$ 
Revised version 3

1 where $f_{W F}$ is the cultivated area divided by the total area when the wildlife-friendly cropping

2 system is adopted. As $d_{W F} \geq d_{I}$, we have $f_{W F} \geq f_{I}$.

The two functions defined by Eqs (3) and (4) can be used to compute the area that can

4 be cultivated by the farmer as a function of a target value $D$ of number of plants per unit area.

5 These two functions are graphically compared in Figure 1. The wildlife-friendly cropping

6 system allows the farmer to cultivate a larger fraction of his field for a given target value $D$.

7 The drawback of this cropping system is that it may lead to a lower total yield than an

8 intensive cropping system. It is thus necessary to compare the crop production and/or the

9 income obtained with two cropping systems to make the final choice.

\section{Crop production assessment}

11 Let $y_{I}$ and $y_{W F}$ denote the yield values obtained in the cultivated part with the intensive and

12 wildlife-friendly cropping systems respectively. The crop production per unit area obtained

13 with the two strategies for a given target number of plants $D$ are noted $P_{I}$ and $P_{W F}$, and are

14 expressed as:

$15 \quad P_{I}=y_{I} \times f_{I}=y_{I} \frac{d_{U}-D}{d_{U}-d_{I}}$

$16 P_{W F}=y_{W F} \times f_{W F}=y_{W F} \frac{d_{U}-D}{d_{U}-d_{W F}}$

Eqs (5) and (6) can be used to compute the crop production obtained with the two

18 strategies. Also, these equations show that the ratio $\frac{P_{W F}}{P_{I}}$ is defined by

$19 \quad R=\frac{P_{W F}}{P_{I}}=\frac{y_{W F} \times\left[d_{U}-d_{I}\right]}{y_{I} \times\left[d_{U}-d_{W F}\right]}$ 


\section{Revised version 3}

$14 \quad d_{u T}=\frac{y_{I} \times d_{W F}-y_{W F} \times d_{I}}{y_{I}-y_{W F}}$ depend on the target value $D$.

$$
d_{u T}=\frac{y_{I} \times d_{W F}-y_{W F} \times d_{I}}{y_{I}-y_{W F}}
$$

The ratio (7) depends on the yields and plant densities obtained with the two cropping systems, and on the plant density obtained in the uncultivated part of the field, but does not

The partial derivatives of $R$ were computed in order to study the sensitivity of $R$ to crop yields and weed densities. The signs of the derivatives show that $R$ increases as a function of $y_{W F}$ and $d_{W F}$, but decreases as a function of $y_{I}, d_{I}$, and $d_{U}$ (Table 1).

The crop production ratio $R$ can be used in two ways. Firstly, it is possible to compute a single $R$ value for a given environment, characterised by a given value of $d_{U}$. This approach is useful in order to compare the crop production obtained with two cropping systems in a specific environment. Secondly, it is possible to compute $R$ for a series of environments characterised by different values of $d_{U}$. This second approach allows one to study the sensitivity of $R$ to the natural abundance of the plant species. It is interesting to calculate the threshold value of $d_{U}$ corresponding to $R=1$. According to Eqn (7), this value is

When $d_{U}$ is equal to $d_{u T}$, the production obtained with the two cropping systems is the same. When $d_{U}$ is higher than $d_{u T}$, the crop production is higher with the intensive cropping system than with the wildlife-friendly cropping system. corresponding gross margins associated with the two cropping systems. This is useful when the prices and the costs associated with the two cropping systems must be taken into account. 
Revised version 3

\section{Estimation}

2 The calculation of $f_{I}$ and $f_{W F}$ requires a knowledge of the plant densities $d_{I}, d_{W F}$, and $d_{U}$.

3 In addition, the calculation of $R$ requires a knowledge of the yield values $y_{I}$ and $y_{W F}$. These

4 can be estimated from yield and plant density measurements performed in cropping system

5 experiments. The experiments must include treatments corresponding to different cropping

6 systems. Yield and natural plant species density must be recorded for each treatment. It is also

7 useful to a have a 'set-aside' treatment in the same field, in which the plant density is

8 recorded. If this treatment is present it is possible to estimate $d_{U}$. If not, it is possible to

9 compute $f_{I}, f_{W F}$, and $R$ for different $d_{U}$ taken within a reasonable range of values as shown 10 below.

12 Case studies

13 Two case studies are presented here for two species with contrasting ecology and preservation 14 goals. The first example is of an Adonis species with very low abundance, at risk of population extinction. In this case the main objective is to preserve low densities of the species to avoid its complete disappearance, but fortunately the target densities are low

17 enough to avoid any crop yield loss. The second example regards a common species (Poa 18 anпua), which is controlled at very low densities in intensive cropping systems, while it is 19 recognised for its ecological function if significant population densities are maintained.

\section{Maintaining the population of an Adonis species}

21 The populations of Adonis species have steadily decreased in Western Europe for several 22 decades. Fifty years ago three species of Adonis (A. aestivalis, A. flammea, A. annua) were 23 still common in wheat fields in France. These species became endangered (less then 1 plant 
Revised version 3

$1 \mathrm{~km}^{-2}$ ) in the 1970s (Aymonin, 1976) and are no longer found in intensive crops. In this case

2 study, we compare two land use strategies for increasing the population of this species in a

3 given arable area cropped with winter wheat. The first strategy consists in using an intensive

4 cropping system characterised by $y_{I}=8 \mathrm{t} \mathrm{ha}^{-1}$ and $d_{I}=0$. These values are commonly

5 observed in France when the crop is cultivated using conventional practices. The second

6 strategy consists in using a wildlife-friendly cropping system characterised by $y_{W F}=6 \mathrm{tha}^{-1}$

7 and by a plant density $d_{W F}$ in the range $0.005-0.01$ plants $\mathrm{m}^{-2}$. These values may be obtained

8 in winter wheat fields with low herbicide use, low sowing densities, late sowing dates

9 associated with a stale seed bed, and low fertiliser inputs. However, the density increase of

10 such a rare species induced by wildlife-friendly practices is highly unpredictable. In Sweden,

11 Rydberg \& Milberg (2000) found rare weed species in organic arable fields, but on a smaller

12 scale in a cropping system experiment in Germany, none of the species recorded on fields

13 with organic systems were considered rare (Gruber et al., 2000). According to Squire et al.

14 (2000), the reduction in herbicide use can result in an increase in the number of weed species,

15 but the commonest species are likely to increase the most, while rarer species are less

16 favoured.

The proportion of the area cultivated $(f)$ and the crop production $(P)$ depend on $D$ (Eqs 3-6) and this dependence is illustrated in Figures $2(a, b)$ and $3(a, b)$ where two values are considered for $D, 0.006$ and 0.009 plants $\mathrm{m}^{-2}$. The higher the value of $D$, the lower is the cultivated area and crop production. The cultivated area is always larger with the wildlifefriendly cropping system than with the intensive cropping system (Figure $2 \mathrm{a}, \mathrm{b}$ ).

Figures $2(a, b)$ and $3(a, b)$ show that the cultivated area and the crop production depend highly on the plant density in the uncultivated land. When the density $d_{U}$ is low, the cultivated area (and therefore crop production) must be significantly reduced to reach the 
Revised version 3

1 target number of plants $D$. For example, when $d_{U}=0.01$ plants $\mathrm{m}^{-2}$, it is necessary to keep

2 more than $80 \%$ of the area uncultivated to reach the target number of plants $D=0.009$ plants $3 \mathrm{~m}^{-2}$ (Figure $\left.2 \mathrm{~b}\right)$.

The values of $d_{u T}$ and $R$ do not depend on the target number of plants $D$ (Eqs 7 and

5 8). If we assume $d_{I}=0, y_{W F}=6 \mathrm{tha}^{-1}$, and $y_{I}=8 \mathrm{t} \mathrm{ha}^{-1}$, the plant density threshold $d_{u T}$ is equal

6 to $4 \times d_{W F}$ (Eqn 8). For example, if the plant density obtained with the wildlife-friendly

7 cropping system is equal to 0.005 plants $\mathrm{m}^{-2}$, the threshold value is equal to $d_{u T}=0.02$ plants

$8 \mathrm{~m}^{-2}$. In this case, the highest winter wheat production is obtained with the intensive cropping

9 system if the plant density in the uncultivated part of the field $\left(d_{U}\right)$ is above 0.02 plants $\mathrm{m}^{-2}$.

10 Alternatively, if the plant density in the uncultivated part of the field is below 0.02 plants $\mathrm{m}^{-2}$,

11 the highest crop production is obtained with the wildlife-friendly cropping system. This is

12 illustrated in Figure $4 \mathrm{a}$ where the values of the crop production ratio $R$ (Eqn 7 ) are reported

13 for a series of values of $d_{U}$. The value of $R$ is more than 1 when the density $d_{U}$ is less than

140.02 plants $\mathrm{m}^{-2}$. This threshold value seems rather low. But the densities of Adonis spp.

15 observed in set-aside in France are generally less than 0.02 plants $\mathrm{m}^{-2}$ (Chauvel, personnal

16 communication). Thus, the strategy based on the wildlife-friendly cropping system will give

17 the highest crop production in most of the environments.

The derivatives presented in Table 1 were used to study the sensitivity of $R$ to crop

19 yield and plant densities. The derivative values were computed for $d_{U}=0.02$ plants $\mathrm{m}^{-2}$, and

$20 d_{W F}=0.005$ or $d_{W F}=0.01$ plants $\mathrm{m}^{-2}$. The results show that $R$ is much more sensitive to the

21 plant densities $d_{I}, d_{W F}$, and $d_{U}$ than to the crop yield values $y_{W F}$ and $y_{I}$ (Table 2). For

22 example, when $d_{W F}=0.005, \frac{\partial R}{\partial d_{W F}}$ is equal to 66.67 but $\frac{\partial R}{\partial y_{W F}}$ is only equal to 0.17 . This is 


\section{Revised version 3}

1 due to the low density values of the Adonis spp. in both cultivated and uncultivated areas. A

2 small increase in $d_{W F}$ leads to a much larger cultivated area and crop production being

3 obtained with the wildlife-friendly cropping system and thus to a much higher value of $R$.

4 Table 2 also shows that $R$ is very sensitive to $d_{U}$, especially when $d_{W F}=0.01$. A small

5 increase of $d_{U}$ leads to a much lower value of $R$. This result is consistent with the response

6 curves shown in Figure 4.

\section{$7 \quad$ Maintaining the population of Poa annua}

8 Poa annua is a grass weed species with a short life cycle and an extended period of

9 emergence in crops, so this species may provide a regular supply of seeds to feed birds and 10 other vertebrates without competing strongly with the infested crop. In addition, the 11 populations of Poa annua host a large number of insect species. It is therefore an important component of the ecosystem (Marshall et al., 2003). In this case study, we compare two land use strategies for increasing the population of this weed species in a winter wheat crop. The

14 first strategy consists of using an intensive cropping system characterised by $y_{I}=8 \mathrm{tha}^{-1}$ and $d_{I}=0$ because of the systematic use of herbicides efficient against this species. The second strategy is to use a wildlife-friendly cropping system characterised by $y_{W F}=6 \mathrm{t} \mathrm{ha}^{-1}$ and by a

17 plant density $d_{W F}$ in the range 20-80 plants $\mathrm{m}^{-2}$. These values may be observed in winter wheat fields in diversified crop rotations with Integrated Weed Management, avoiding among other things the use of urea herbicides, and in organic farming (Mortensen et al., 2000).

The cultivated area and the crop production values (Eqs 3-6) are shown in Figures 2 (c, d) and 3 (c, d) for $d_{W F}=20$ and for two values of $D, 50$ and 80 plants $\mathrm{m}^{-2}$. These target density values are high enough to ensure a good accessibility of the weed resources to other trophic groups (birds, carabids etc.). Here also, the cultivated area is invariably larger with the 
Revised version 3

1 wildlife-friendly cropping system than with the intensive cropping system (Figure 2). Figure 3

2 (c, d) shows that the crop production obtained with the intensive cropping system is higher

3 than that obtained with the wildlife-friendly cropping system for all the tested values of $d_{U}$

4 when $d_{W F}=20$. Figures 2 (c, d) and 3 (c, d) also show that when the density $d_{U}$ is low, it is 5 necessary to greatly reduce the cultivated area (and hence the crop production) to reach the 6 target number of plants $D$. For example, when $d_{W F}=20$ and $d_{U}=100$ plants $\mathrm{m}^{-2}$, almost all the 7 land must be kept uncultivated to reach the target number of plants $D=80$ plants $\mathrm{m}^{-2}$ (Figure $8 \quad 3 d)$.

Here also, the plant density threshold $d_{u T}$ (Eqn 8 ) is equal to $4 \times d_{W F}$. For example, if

10 the plant density obtained with the wildlife-friendly cropping system is 20 plants $\mathrm{m}^{-2}$, the 11 threshold value is $d_{u T}=80$ plants $\mathrm{m}^{-2}$. In this case, the highest winter wheat production is obtained with the intensive cropping system if the plant density in the uncultivated part of the 13 field $\left(d_{U}\right)$ is higher than 80 plants $\mathrm{m}^{-2}$.

Figure $4(\mathrm{c}, \mathrm{d})$ shows the values of the crop production ratio $R$ (Eqn 7 ) for a series of values of $d_{U}\left(100-400\right.$ plant. $\left.\mathrm{m}^{-2}\right)$ and for two contrasting values of $d_{W F}, 20$ and 80 plants $\mathrm{m}^{-2}$. When $d_{W F}=20$, the value of $R$ is lower than 1 for all the tested values of $d_{U}$ (Figure 4c). This

17 is because, in this case, $d_{u T}=80$ plants $\mathrm{m}^{-2}$ and all the tested values of $d_{U}$ are above this threshold. Conversely, when $d_{W F}=80, R$ is more than 1 for most of the tested values of $d_{U}$

19 (Figure $4 \mathrm{~d}$ ). $R$ values of less than 1 are obtained only when $d_{U}$ exceeds 320 plants $\mathrm{m}^{-2}$. The derivatives of $R$ were computed for $d_{U}=200$ plants $\mathrm{m}^{-2}$ and $d_{W F}=20$ or $d_{W F}=80$

21 plants $\mathrm{m}^{-2}$ (Table 2). The results show that $R$ is less sensitive to the plant densities $d_{I}, d_{W F}$, and $d_{U}$ than to the crop yield values $y_{W F}$ and $y_{I}$. This is because the plant densities $d_{W F}$ and 
Revised version 3

$1 d_{U}$ are high and because the difference between these densities is large. A small increase or

2 decrease in plant density does not significantly affect the crop production ratio.

3

\section{Discussion}

5 The theoretical analysis of two strategies of management of agricultural areas presented in 6 this paper is an attempt to study the trade-off between wildlife conservation and crop 7 production, adapted to the particular case of plant species referred to as 'weeds', because their 8 typical environment is cultivated fields and their surroundings. Green et al. (2005) considered

9 a similar problem at the regional level, comparing two options, namely (a) wildlife-friendly

10 farming on the whole area and (b) land sparing, with a proportion of land devoted to wildlife 11 conservation and the remainder devoted to crop production. These authors showed that the 12 optimal choice between these options depends on the shape of the relationship between 13 wildlife density and crop production. In our approach, the best land use strategy is not determined from the shape of yield-density relationship but from values of crop yield and weed densities. The validity of our model and of the numerical results is discussed below.

\section{Estimation of the model parameters}

17 Crop yields and weed densities can be estimated from experiments or farmers' field surveys.

18 Due to the widespread use of herbicides, weed densities are often very low, for most species.

19 Indeed, only a few species, which are not very sensitive to the herbicides, can develop dense

20 populations (e.g. Colbach et al., 2000). Adonis species have almost completely disappeared 21 from areas with intensive agriculture (Pichot, 1991), either because they are sensitive to 22 herbicide or because populations of these species need particular environmental conditions to 23 grow (e.g light availability throughout the plant life cycle) that are not met in current intensive 
Revised version 3

1 dense crop canopies boosted by high nitrogen fertiliser inputs (Kleijn \& van der Voort, 1997).

2 In contrast, Poа апnua is a very widespread species that was found in 11 to $100 \%$ of the fields

3 in different European regions on a North-South transect from Sweden to Italy (Radics et al.,

4 2000), and ranked the second most frequently occurring weed species for the frequency of

5 presence in a large field survey conducted in winter cereals in the UK in 1988 (Whitehead \&

6 Wright, 1989). However, it is well controlled by herbicide programmes in wheat crops in

7 most regions with intensive cropping systems. It is therefore reasonable to choose a density of

8 zero for both species in intensive cropping systems in the simulation analysis.

The density of weeds of ecological interest in more wildlife-friendly cropping systems may be derived either from old surveys of weed flora performed before the increase in

11 herbicide and nitrogen use, from recent surveys of organic farming (Hyvönen et al., 2003; Rydberg \& Milberg, 2000), or from long-term experiments aimed at testing the feasibility of 13 cropping systems based on the principles of Integrated Pest Management. However, there 14 may be large differences in plant density for a given species between different fields, from 15 different soil and climatic conditions and conducted with different "low-input" cropping 16 systems (e.g. Marshall \& Arnold, 1994), so the plant density to be expected in a wildlife17 friendly cropping system is highly unpredictable.

In uncultivated areas, even less information is available regarding the density of

19 "weed" species although, as shown in this paper, the choice of the strategy that supports best 20 biological diversity depends on this information.

Crop yield and weed values are always variable and imperfectly estimated. It is thus necessary to deal with this uncertainty using, for example, the expression of the derivatives of $R$ given in this paper. In all cases, we advise to perform a sensitivity analyse of the ratio $R$ to 24 crop yield and weed density values. Note that, in some practical applications, it may be useful 
Revised version 3

1 to use gross margins instead of crop yields in order to account for fertiliser and pesticide

2 prices.

\section{Validity of the model equations}

4 The equations presented in this paper are based on the hypothesis that the density of weed

5 species would be higher in uncultivated areas than in low-input cropping systems. This

6 hypothesis is debatable: indeed some weed species grow preferentially in cultivated fields,

7 where they can find an environment favourable to their life history (for example: short life

8 cycle, seed dormancy, seed persistence in the soil, seasonal emergence, high level of seed

9 production).

It has never been demonstrated that Adonis species would develop stable populations

11 in uncultivated areas. In long-term set-aside, the overall soil seed bank is likely to increase

12 dramatically if various annual species produce seeds. However, the growing environment

13 would become strongly competitive after a few years, which is probably not favourable for

14 Adonis spp.. If annual species are not allowed to produce seeds, for example through repeated

15 mowing, then the proportion of perennials is likely to change more rapidly, which would also

16 provide a very competitive environment for young Adonis seedlings. Poa annua is a very

17 short-stemmed species, which would also have difficulty developing stable populations in

18 long term set-aside with a dense competitive canopy.

Short-term set-aside, rotating each year in the landscape, are likely to provide more

20 open canopies that would be much more favourable for weakly competitive species such as

21 Adonis spp. and P. annua. However, in rotational set-aside, the presence of a species is

22 strongly related to the presence of a significant number of seeds in the seed bank, and this is

23 unlikely for a species that has been very rarely observed in a given landscape for many years,

24 such as Adonis spp.. 
Revised version 3

\section{Relative performance of the land use strategies}

2 The first case study presented above showed that, for the Adonis spp., the value of the crop 3 production ratio $R$ (Eqn 7) is highly sensitive to density in the wildlife-friendly cropping 4 system $\left(d_{W F}\right)$ and to the density in uncultivated areas $\left(d_{U}\right)$. If $d_{W F}$ is set at 0.005 plants $\mathrm{m}^{-2}$ 5 (Figure 4a), the ratio $R$ shifts from highly favourable to the wildlife-friendly cropping system 6 when $d_{U}=0.01$ plants $\mathrm{m}^{-2}$ to more favourable to the intensive system when $d_{U}=0.04$ plants

$7 \mathrm{~m}^{-2}$. The fourfold increase in weed density is not dramatic compared with the wide range of 8 densities observed in cultivated fields. If the Adonis spp. density is low both in cultivated 9 areas with low inputs and in uncultivated areas, then the objective of maintaining a significant 10 population in the landscape will be reached only with a severe decline in the proportion of the 11 area cultivated (Figure $2 \mathrm{~b}$ ), and therefore a proportional decline in the crop production, which is likely to be unacceptable for social reasons.

For $P$. annua, the ratio $R$ is less sensitive to plant density, but the conclusions are different depending on whether a high or a low value is assumed for $d_{W F}$. If $d_{W F}$ is about 20 plants $\mathrm{m}^{-2}$, the land-sparing option with intensive cropping is more favourable for all the explored values of density in uncultivated areas. However, if the density $d_{W F}$ is about 80 plants $\mathrm{m}^{-2}$, which is only four times higher, then the wildlife-friendly cropping system is more profitable for most of the explored values of density in uncultivated areas.

The results of the calculations should be considered with caution because of the uncertainty regarding the contribution of target species in uncultivated areas. However, we can still make an attempt to identify some trends for land use recommendation as far as weed species conservation is concerned. For rare species such as Adonis spp., it is likely that plant density in uncultivated areas devoted to wildlife conservation would be only slightly higher than in low-input wildlife-friendly cropping systems. This corresponds to the left-hand part of Figures $4 \mathrm{a}$ and $4 \mathrm{~b}$, where the ratio $R$ indicates higher overall crop production with the low- 
Revised version 3

1 input wildlife-friendly cropping system. For common species with low competitive ability

2 such as $P$. annua, a density of 80 plants $\mathrm{m}^{-2}$ seems likely to be reached and maintained in a

3 low-input cropping system, and the density in uncultivated areas would be only slightly

4 higher. These hypotheses correspond to the left-hand part of the Figure 4d, which is again

5 more favourable to the low-input wildlife-friendly cropping system.

6

\section{Conclusion}

8 The model presented in this paper can be used to compare the relative performance of

9 wildlife-friendly cropping system and land sparing for maintaining a desirable level of

10 abundance of a given species of interest in agricultural areas. We showed that the relative

11 performance of the two strategies depends on the plant densities in cultivated fields and

12 uncultivated areas, but does not depend on the desired level of abundance of the species of

13 interest. This result emphasises the need for more comprehensive knowledge about the effects

14 of management options on weed species of ecological value in both uncultivated areas and 15 low-input cropping systems.

\section{References}

18 Andreasen C, Stryhn H \& Streibig JC (1996) Decline in the flora in Danish arable fields.

19 Journal of Applied Ecology 33, 619-626.

20 AyMONIN GG (1976) La baisse de la diversité spécifique dans la flore des terres cultivées. In:

21 Vème Colloque International sur l'Ecologie et la Biologie des Mauvaises Herbes, Dijon, 22 France, 195-202. 
Revised version 3

1 Chamberlain DE, Fuller RJ, Bunce JC, Duckworth JC \& ShrubB M (2000) Changes in

2 the abundance of farmland birds in relation to the timing of agricultural intensification in

3 England and Wales. Journal of Applied Ecology 37, 771-788.

4 Colbach N, Dessaint F \& Forcella F (2000) Evaluating field-scale sampling methods for

5 the estimation of mean plant densities of weeds. Weed Research 40, 411-430.

6 DE SNOO GR (1997) Arable flora in sprayed and unsprayed crop edges. Agriculture,

7 Ecosystems and Environment 66, 223-230.

8 Gerowitt B, Bertke E, Hespelt SK \& Tute C (2003) Towards multifunctional agriculture -

9 weeds as ecological goods? Weed Research 43, 227-235.

10 GREEN RE, CORNELl SJ, SCHARLEMANN JPW \& BALMFORD A (2005) Farming and the fate of 11 wild nature. Science 307, 550-555.

12 Gruber H, Handel K \& Broschewitz B (2000) Influence of farming system on weeds in 13 thresh crops of a six-year crop rotation. Zeitschrift Fur Pflanzenkrankheiten Und 14 Pflanzenschutz-Journal of Plant Disease and Protection S7, 33-40.

15 Hyvönen T, Ketoja E, Salonen J, Jalli H \& Tiainen J (2003) Weed species diversity and 16 community composition in organic and conventinal cropping of spring cereals. Agriculture, 17 Ecosystems and Environment 97, 131-149.

18 KLEIJN D \& VAN DER VOORT LAC (1997) Conservation headlands for rare arable weeds: the

19 effects of fertiliser application and light penetration on plant growth. Biological Conservation $20 \quad 81,57-67$.

21 MARShall EJP \& ARnOld GA (1994) Weed seed bank in arable fields under contrasting 22 pesticide regimes. Annals of Applied Biology 125, 349-360. 
Revised version 3

1 Marshall EJP \& MoONEN AC (2002) Field margins in northern Europe: their functions and

2 interactions with agriculture. Agriculture, Ecosystems and Environment 89, 5-21.

3 Marshall EJP, Brown VK, Boatman ND, LutMan PJW, SQuire GR \& WARd LK (2003)

4 The role of weeds in supporting biological diversity within crop fields. Weed Research $\mathbf{4 3}$, $5 \quad 77-89$.

6 Mortensen DA, BastiaAns L \& SATtin M (2000) The role of ecology in the development of

7 weed management systems: an outlook. Weed Research 40, 49-62.

8 Pichot A (1991) Evolution de la flore adventice et de son contrôle en Beauce depuis 50 ans.

9 Comptes Rendus de l'Académie d'Agriculture de France 77, 117-127.

10 Radics L, Glemnitz M, Hoffmann J \& Czimber GY (2000) Comparative investigation on 11 weed flora comopsitionalong a climatic gradientin Europe as basis for climate change 12 research efforts. In: Proceedings 11th International Conference on Weed Biology, Dijon, 13 France, 191-199.

14 Rydberg NT \& Milberg P (2000) A survey of weeds in organic farming in Sweden. 15 Biological Agriculture and Horticulture 18, 175-185.

16 Stoate C, Boatman nd, Borralho RJ, Rio Carvalho C, De Snoo GR \& Eden P (2001) 17 Ecological impacts of arable intensification in Europe. Journal of Environmental 18 Management 63, 337-365.

19 SutclifFE OL \& KAY QON (2000) Changes in the arable flora of central southern England 20 since the 1960s. Biological Conservation 93, 1-8.

21 Squire GR, Rodger S \& Wright G (2000) Community-scale seedbank responses to less 22 intense rotation and reduced herbicide input. Annals of Applied Biology 136, 47-57. 
Revised version 3

1 VAN WENUM JH, WOSSINK GAA \& RENKEMA JA (2004) Location-specific modeling for 2 optimizing wildlife management on crop farms. Ecological Economics 48, 395-407.

3 WhiteHEAD R \& WRIGHT HC (1989) The incidence of weeds in winter cereals in Great

4 Britain. In: Proceedings 1989 Brighton Crop protection Conference - Weeds, Brighton, UK, $5 \quad 107-112$.

6 


\section{Revised version 3}

1 Table 1. Expressions and signs of the derivatives of $R=\frac{y_{W F} \times\left(d_{U}-d_{I}\right)}{y_{I} \times\left(d_{U}-d_{W F}\right)}$. It is assumed that

$2 \quad d_{U}>d_{W F}>d_{I}$.

3

Derivative

$$
\frac{\partial R}{\partial y_{W F}}=\frac{d_{U}-d_{I}}{y_{I} \times\left(d_{U}-d_{W F}\right)}
$$$$
\frac{\partial R}{\partial y_{I}}=\frac{-y_{W F} \times\left(d_{U}-d_{I}\right)}{y_{I}^{2} \times\left(d_{U}-d_{W F}\right)}
$$$$
\frac{\partial R}{\partial d_{W F}}=\frac{y_{W F} \times\left(d_{U}-d_{I}\right)}{y_{I} \times\left(d_{U}-d_{W F}\right)^{2}}
$$

$$
\frac{\partial R}{\partial d_{I}}=\frac{-y_{W F}}{y_{I} \times\left(d_{U}-d_{W F}\right)}
$$

$$
\frac{\partial R}{\partial d_{U}}=\frac{y_{W F} \times\left(d_{I}-d_{W F}\right)}{y_{I} \times\left(d_{U}-d_{W F}\right)^{2}}
$$

Sign

$+$

$+$ 
Revised version 3

1

2 Table 2. Values of the derivatives of $R$ for $y_{I}=8 \mathrm{t}^{-h a^{-1}}, y_{W F}=6 \mathrm{t}^{-h^{-1}}, d_{I}=0$, and for low and high

3 densities $d_{W F}$ of Adonis sp. and Poa annua.

4

\begin{tabular}{|c|c|c|c|c|c|c|c|}
\hline & & & \multicolumn{5}{|c|}{ Values of the derivatives of $R$} \\
\hline \multirow{2}{*}{ (plants $\mathrm{m}^{-2}$ ) } & -2 & $R$ & $\partial R$ & $\partial R$ & $\partial R$ & $\partial R$ & $\partial R$ \\
\hline & & & $\partial y_{W F}$ & $\partial y_{I}$ & $\partial d_{W F}$ & $\partial d_{I}$ & $\partial d_{U}$ \\
\hline
\end{tabular}

Adonis sp.

$\begin{array}{lrrrrrrr}0.005 & 0.02 & 1 & 0.17 & -0.125 & 66.67 & -50 & -16.17 \\ 0.01 & 0.02 & 1.5 & 0.25 & -0.19 & 150 & -75 & -75\end{array}$

Poa annua

\begin{tabular}{rrrrrrrr}
20 & 200 & 0.83 & 0.14 & -0.104 & 0.004 & -0.0042 & -0.00046 \\
80 & 200 & 1.25 & 0.21 & -0.156 & 0.01 & -0.0063 & -0.0042 \\
\hline
\end{tabular}

5

6 
Revised version 3

\section{Figure captions}

2

3 Figure 1. Relationship between the target number of plants per unit area $(D)$ and the fraction

4 of the field area that can be cultivated $(f)$ with an intensive cropping system (continuous line) and with a wildlife-friendly cropping system (dashed line).

7 Figure 2. Ratio of the cultivated area to the total area obtained with the wildlife-friendly 8 cropping system (bold line) and with the intensive cropping system (thin line) for Adonis (a, b) and Poa annua (c, d). For Adonis, the calculations were performed with $d_{W F}=0.005$ plants

$10 \mathrm{~m}^{-2}$, and $D=0.006$ plants $\mathrm{m}^{-2}$ (a) or $D=0.009$ plants $\mathrm{m}^{-2}(\mathrm{~b})$, and the value of $d_{U}$ was in the 11 range 0.01-0.1 plants $\mathrm{m}^{-2}$. For Poa annua, the calculations were performed with $d_{W F}=20$ 12 plants $\mathrm{m}^{-2}$, and $D=50$ plants $\mathrm{m}^{-2}$ (c) or $D=80$ plants $\mathrm{m}^{-2}(\mathrm{~d})$, and the value of $d_{U}$ was in the 13 range $100-400$ plants $\mathrm{m}^{-2}$.

15 Figure 3. Crop production obtained with the wildlife-friendly cropping system (bold line) and with the intensive cropping system (thin line) for Adonis (a, b) and Poa annua (c, d). For

17 Adonis, the calculations were performed with $d_{W F}=0.005$ plants $\mathrm{m}^{-2}$, and $D=0.006$ plants $\mathrm{m}^{-2}$ 18 (a) or $D=0.009$ plants $\mathrm{m}^{-2}$ (b), and the value of $d_{U}$ was in the range $0.01-0.1$ plants $\mathrm{m}^{-2}$. For 19 Poa annua, the calculations were performed with $d_{W F}=20$ plants $\mathrm{m}^{-2}$, and $D=50$ plants $\mathrm{m}^{-2}$ (c) or $D=80$ plants $\mathrm{m}^{-2}(\mathrm{~d})$, and the value of $d_{U}$ was in the range $100-400$ plants $\mathrm{m}^{-2}$. 
Revised version 3

1 Figure 4. Ratio $(R)$ of the crop production obtained with the wildlife-friendly cropping system

2 to the crop production obtained with the intensive cropping system for Adonis (a, b) and Poa

3 annua (c, d). For Adonis, the calculations were performed with $d_{W F}=0.005$ plants $\mathrm{m}^{-2}$ (a) and

$4 d_{W F}=0.01$ plants $\mathrm{m}^{-2}(\mathrm{~b})$, and the value of $d_{U}$ was in the range 0.01-0.1 plants $\mathrm{m}^{-2}$. For Poa

5 annua, the calculations were performed with $d_{W F}=20$ plants $\mathrm{m}^{-2}$ (c) and $d_{W F}=80$ plants $\mathrm{m}^{-2}$

6 (d), and the value of $d_{U}$ was in the range 100-400 plants $\mathrm{m}^{-2}$.

7

8 
Revised version 3

1 Figure 1

2

3

4

$f$

5

6

7

8

9

10

11

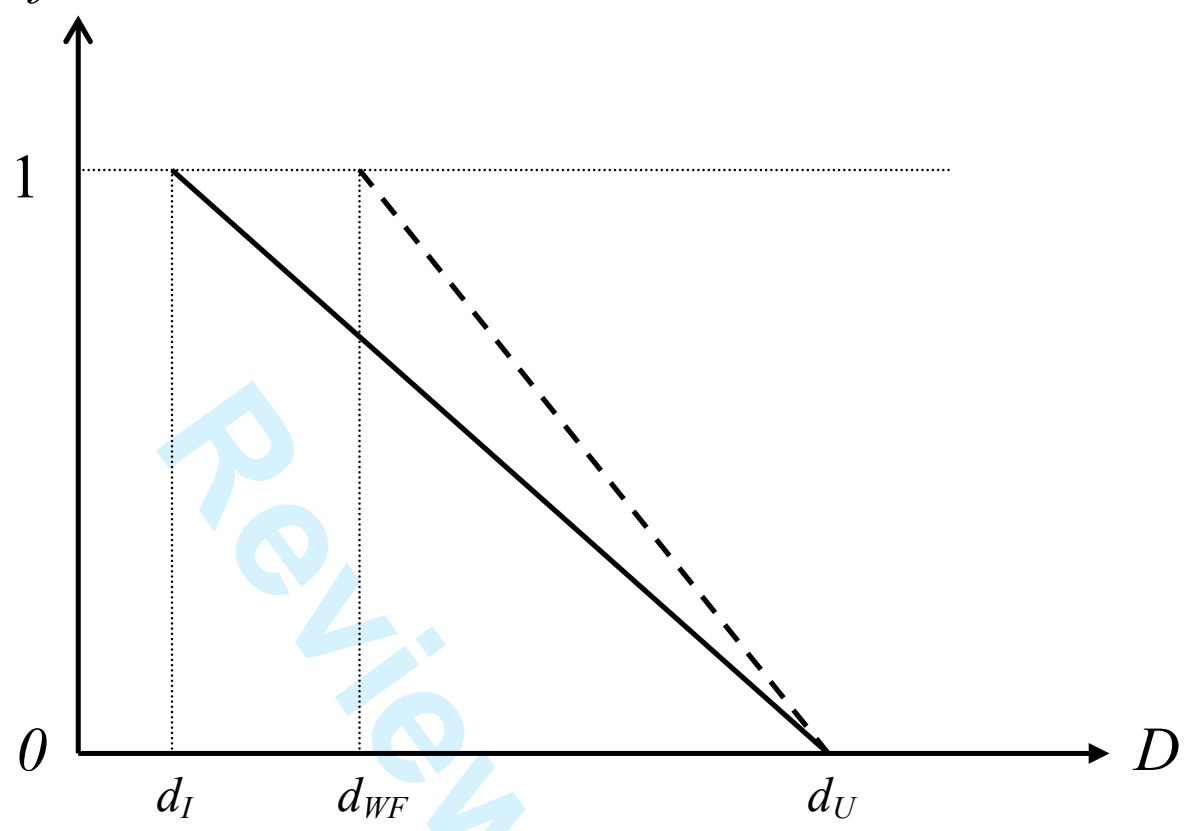

12

13

14 
Revised version 3

$1 \quad$ Figure 2

2
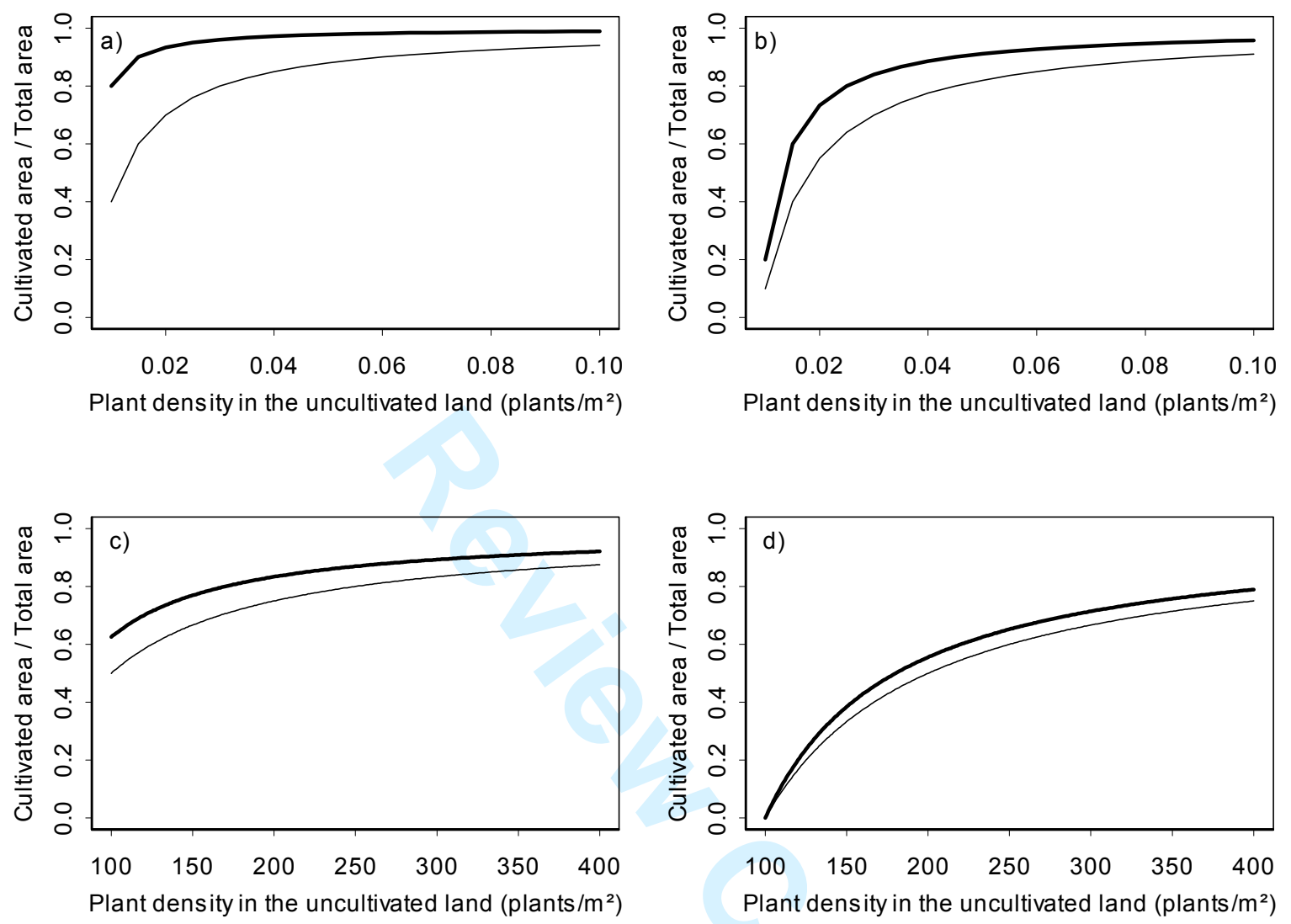


\section{Revised version 3}

\section{Figure 3}

2
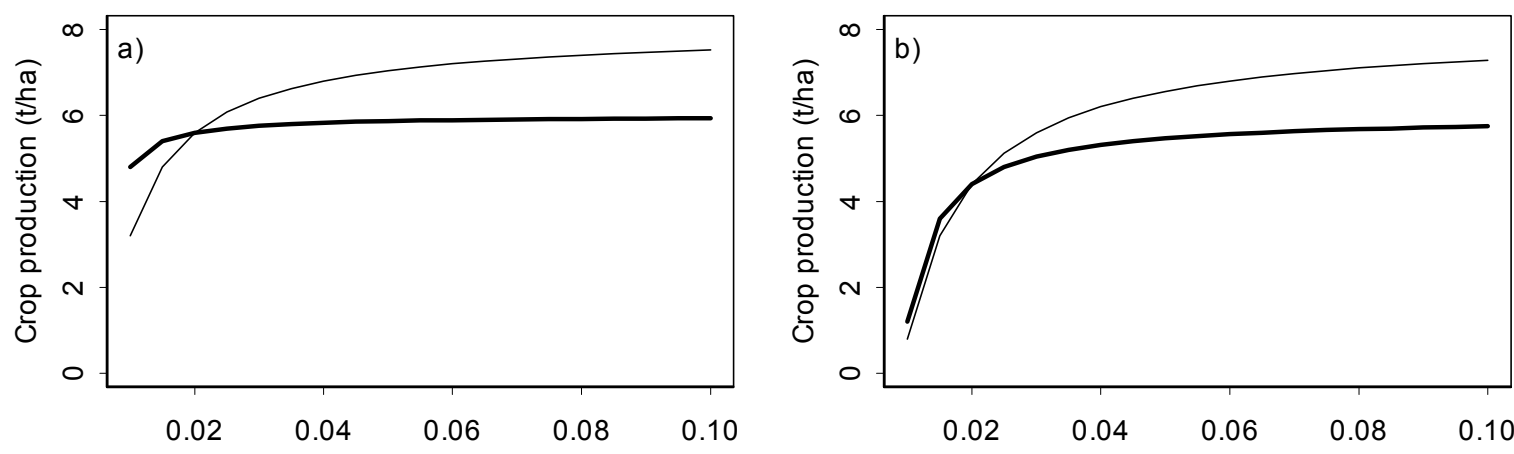

Plant density in the uncultivated land (plants $/ \mathrm{m}^{2}$ )

Plant density in the uncultivated land (plants $/ \mathrm{m}^{2}$ )
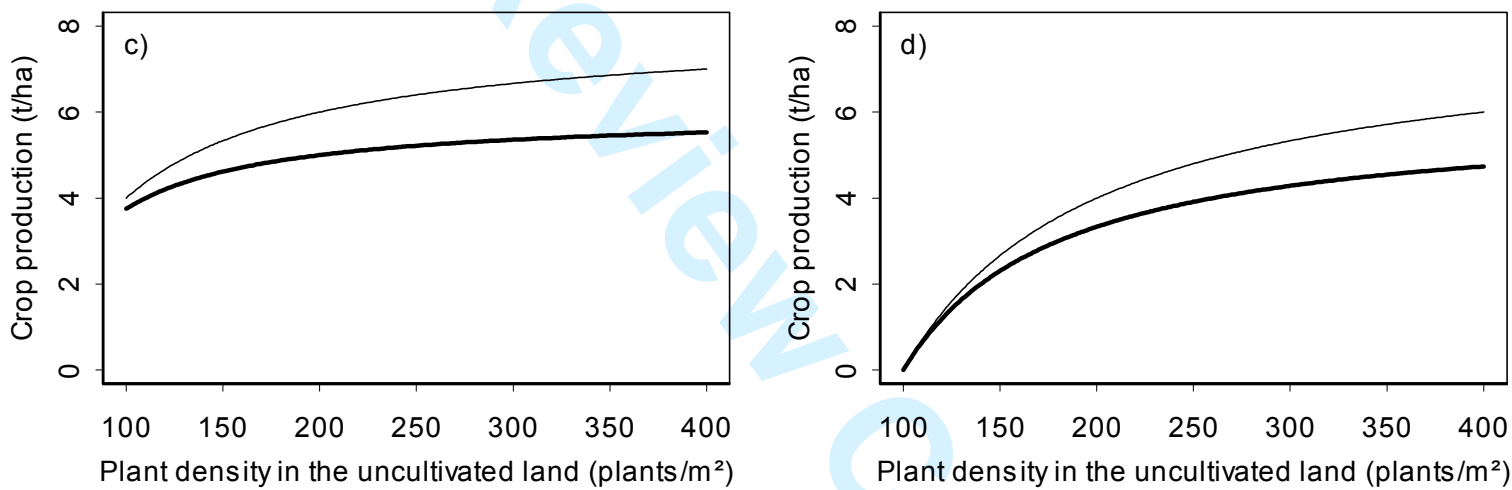
Revised version 3

$1 \quad$ Figure 4

2

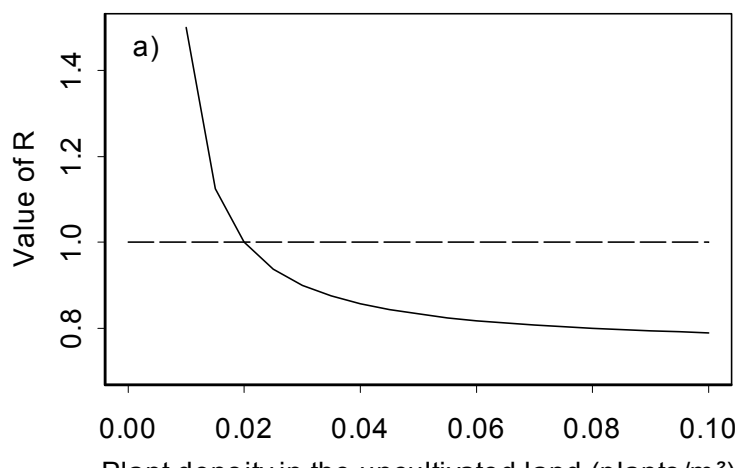

Plant density in the uncultivated land (plants $/ \mathrm{m}^{2}$ )

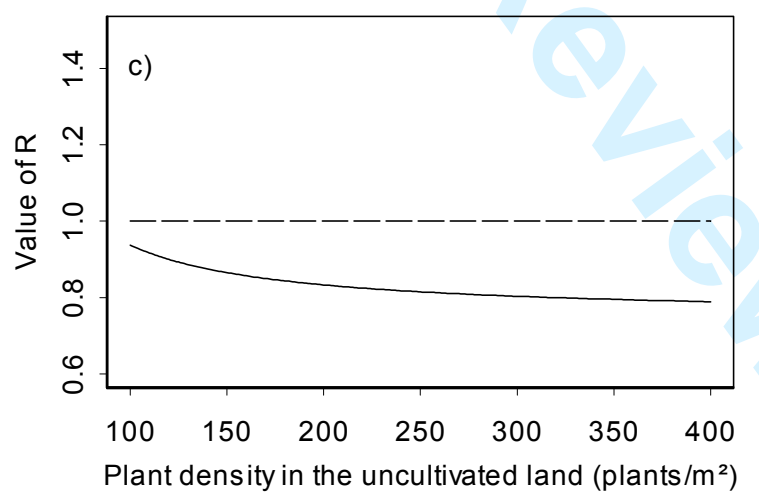

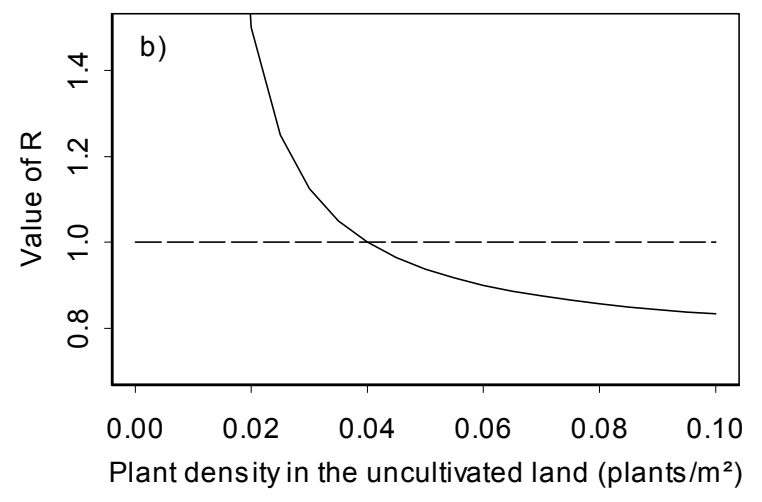

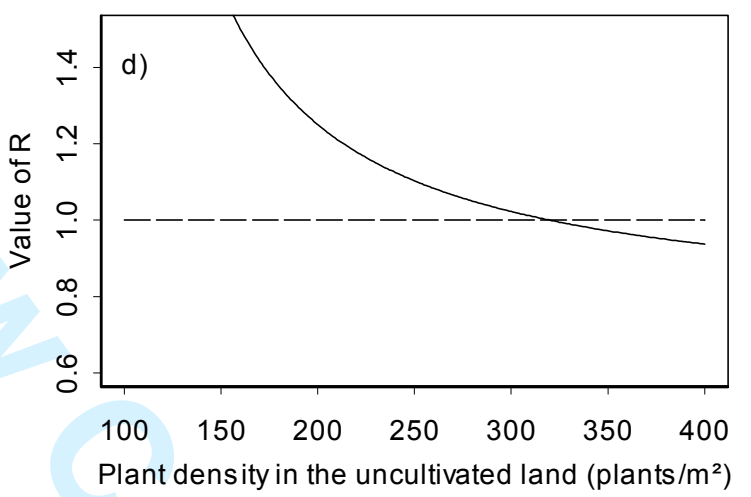

